\section{Estructuración del espacio público entre política y fiesta: el caso de plaza Italia en Santiago, Chile}

\author{
Alejandro Gana Núñez \\ ORCID: https://orcid.org/0000-0002-1884-643X \\ Corporación Carnaval de Coplas por Valparaíso, Valparaíso, Chile. \\ Correo electrónico: cccv@valparaisoinmaterial.cl
}

\begin{abstract}
Resumen
Este artículo busca aproximarse al fenómeno de plaza Dignidad en Santiago de Chile como un espacio público de gran trascendencia social y simbólica, de escala metropolitana y alcance nacional, en especial, a partir del proceso de movilización social desde octubre de 2019. En este trabajo se analizan los factores para la conformación, durante el siglo XX, de plaza Italia, como un conjunto monumental para el encuentro, la recreación y la manifestación, así como también las dimensiones de espacio público y flujo, como elementos morfológicos y urbanos que dan cuenta de la estructuración histórica de este lugar emblemático. Plaza Italia, plaza Baquedano y plaza Dignidad: tres denominaciones y distintas representaciones que conviven y se contradicen en el espacio urbano, como escenario de procesos de enunciación, expresión política y expresión festiva.
\end{abstract}

\section{Palabras clave}

Espacio público, expresión festiva, historia urbana, plaza Italia, representaciones sociales

\section{Structuration of public space between politics and festivity: the case of plaza Italia in Santiago, Chile}

\begin{abstract}
This article aims to approach the phenomenon of plaza Dignidad in Santiago de Chile, as a public space of great social and symbolic relevance, of metropolitan scale and national extent, especially as from the context of social protest, since October 2019. This work analyzes the factors for the conformation, during the twentieth century, of Plaza Italia, as a monumental complex for meeting, recreation, and demonstration, but also the dimensions of public space and flow, as morphological and urban elements that account for the historical structuring of this emblematic place. Plaza Italia, plaza Baquedano and plaza Dignidad: three denominations and different representations that coexist but confront each other in the urban space, as the scenario of processes of enunciation, political and festive expression.
\end{abstract}

\section{Keywords}

Festive expression, Plaza Italia, public space, social representations, urban history 


\section{Introducción}

Luego de la aprobación en el Congreso del retiro del 10\% de los fondos de las Aseguradoras de Fondos de Pensiones (AFP), resonaron espontáneamente las bocinas en señal de festejo en las cercanías de plaza Dignidad, en Santiago de Chile. Sin una convocatoria ni un acuerdo previo, el solo hecho de pasar por ese lugar exige en estos días una acción declamatoria, una toma de posición sobre la actualidad política y social.

El proceso de movilización social vivido en Chile desde octubre de 2019 convocó nuevamente a la ciudadanía a los espacios públicos, a salir del ámbito de la privacidad, a compartir, organizarse y disfrutar de las plazas y parques. Un caso emblemático es el de plaza Italia en Santiago, llamada también plaza Baquedano, y resignificada como plaza Dignidad. La ocupación masiva y continuada de este espacio por millones de personas trascendió la protesta puntual y el festejo deportivo: la toma de la plaza trajo una transformación física, simbólica y semántica, que aquí se analiza con gran interés, pues se observa que no se trata de un fenómeno aislado, sino de un proceso social y cultural expresado en el escenario de la ciudad.

La plaza, en los diversos significados abordados por Topalov (2010), como espacio público abierto destinado al descanso, la recreación y el ocio ha tenido históricamente múltiples usos: mercado, espacio de deliberación, celebración y religiosidad. Estos múltiples roles históricos forman parte de la complejidad del espacio público, representando no solo una forma y función específica, sino también la suma de experiencias y recuerdos sobre el lugar.

En términos de delimitaciones y denominaciones, plaza Baquedano refiere a la plaza circular central, aunque también a cómo se denomina el conjunto completo desde lo institucional. Plaza Italia, en cambio, correspondería a todo el conjunto paisajístico, la rotonda y las áreas verdes aledañas, así como también a la denominación popular de dicho punto de encuentro durante el siglo XX (Orozco, 2018). Plaza Dignidad, por otro lado, sería la denominación popular de la zona en general, surgida a partir de las movilizaciones de octubre de 2019 en adelante.
Este trabajo propone al respecto la siguiente hipótesis: los elementos morfológico-históricos y las representaciones del espacio público de plaza Italia, vinculados a procesos sociales y culturales de alcance urbano y nacional, dan forma a una plaza del Pueblo, que frente la ausencia de otro espacio central que se constituya como lugar de expresión política y festiva en Santiago de Chile, entra en contradicción con la construcción simbólica institucional de la plaza Baquedano. En el contexto de movilización social de fines de 2019, plaza Italia es resignificada y renombrada como plaza Dignidad.

¿Cómo enfrentar en el análisis un vínculo así de estrecho entre espacio urbano historizado y expresión social? Para responderlo, se analizarán las condiciones morfológicas del espacio urbano de plaza Italia para constituirse como lugar de expresión social y política, lo cual implica preguntarse por cómo fue diseñado y cómo ha sido intervenido históricamente, así como también, por cómo se ha construido como lugar de encuentro y de flujo en relación con el crecimiento de la ciudad. Luego, el artículo indaga en cómo se enfrentan y complementan las representaciones institucionales, sociales y de expresión cultural, sobre el caso analizado, para la construcción y resignificación del espacio simbólico, lo cual implica también comprender el espacio en relación con las distintas acciones de enunciación.

\section{Marco teórico}

\section{Calidad del espacio público como diversidad}

En la discusión urbanística, la calidad del espacio público radica en posibilitar relaciones sociales, acoger diversidad o estimular la identificación, la expresión y la integración cultural (Segovia y Neira, 2005). Esto implica considerar que determinados atributos espaciales y morfológicos permiten o facilitan dinámicas sociales. Una mirada sobre la estructura urbana como proceso histórico tendría que hacerse cargo tanto de los atributos del espacio, como de las representaciones y discursos, en relación recíproca. 
Respecto de la discusión acerca del espacio público en la actualidad y sus atributos para el ejercicio de la ciudadanía y el desarrollo de lo público - como escenario de diversidad y diálogo- se revisan aquí distintas referencias que pueden guiar la reflexión sobre cómo entender el fenómeno específico de la construcción de plaza Italia.

Un primer elemento del espacio público para constituirse como lugar de encuentro es la accesibilidad, también factor de la centralidad, la cual contribuye a la concentración de relaciones sociales. La atracción de flujos e interacciones de escala metropolitana, en los espacios centrales, permite además que las relaciones y expresiones sociales tengan un alcance en la opinión pública y, por tanto, pasen a constituirse como espacio de innovación cultural en términos de Castells (1972).

La accesibilidad del espacio público, en cambio, en la acepción de igualdad en el acceso, tiene consecuencias en la construcción de ciudadanía, al favorecer o dificultar la presencia y expresión de diversidad social y cultural sin exclusiones. En este sentido, el espacio es público en tanto no sea controlado por individualidades o sectores de interés específicos, y permita la mezcla de grupos y clases diferentes, pues le concierne a la comunidad entera.

La impersonalidad, propia del ámbito de lo público, es entendida como la interacción entre extraños, en oposición al espacio primario, de la familia, del trabajo. Cabe de todas formas plantearse si dicha oposición es tal, o más bien hay una vinculación entre lo público y lo privado en el espacio público, pues como señala Varela (1999) el derecho a la ciudad tendría que ver no solo con la posibilidad de usar sino también interpretar y, en este sentido, "privatizar" lo público.

Para Borja y Muxí (2003), la calidad del espacio público se establece también en función de la calidad de las relaciones sociales que facilita, donde la diversidad - como mixtura de grupos y de comportamientos- es fundamental para estimular la identificación simbólica y la integración cultural.
Sin embargo, la heterogeneidad social del espacio público no es independiente del entorno construido donde este se emplaza. Jacobs (2011, p. 129) plantea al respecto que "los parques son hijos de sus contornos", cuya diversidad de actividades, flujos y horarios determinan la presencia y diversidad de personas en estos espacios. Adicionalmente, la heterogeneidad y la polifuncionalidad de los espacios urbanos son aspectos que pueden intervenir en la percepción sobre los espacios, para atraer a las personas y motivar el encuentro social, al dotar a los lugares de un carácter vivo, dinámico y fascinante (Varela, 1999, p. 9). Por tanto, junto con la accesibilidad, la heterogeneidad social y la polifuncionalidad son factores de la capacidad de encuentro en el espacio público.

Ahora, en el plano de los espacios públicos en la actualidad, las posibilidades de reconocimiento mutuo y de formar parte de una comunidad política - como factores del desarrollo de la ciudadanía- se ven dificultadas en contextos de alta segregación y de limitación de la diversidad socioeconómica. El proceso de fragmentación urbana en ciudades fuertemente desiguales se traduce en desarticulación y desintegración social (Carrión, 2007), así como en la búsqueda por parte de las élites de establecer comunidades aisladas y homogéneas internamente. La versión chilena de este proceso fue descrita por Alfredo Rodríguez (1984) ya durante la dictadura, planteando que mientras la represión reordenaba el espacio social, el mercado redistribuía el espacio urbano, segregando en función del ingreso.

En esta línea, Azocar (2006) describe cómo en el contexto de la posmodernidad se consolida el debilitamiento de lo público en función de las soluciones individuales o privadas. El conjunto de decisiones individuales de movimiento y flujo no constituye por sí espacio público y, por tanto, desde esta perspectiva se augura la desestructuración de este, y su neutralización en espacios residuales. Borja (2003) define este fenómeno como "agorafobia" o la percepción del espacio público como no protegido o peligroso, pero además como la desconfianza frente al espacio de lo público. 
Queda en discusión evaluar si estos procesos son aún observables en el caso de estudio, sobre todo teniendo en consideración los efectos que la movilización social desde octubre de 2019 generó no solo en plaza Italia, sino en otros espacios públicos centrales en Chile.

\section{La construcción institucional y popular del espacio}

El espacio público es construido y transformado y, por tanto, conlleva una historicidad. Las intervenciones deliberadas y conscientes sobre el espacio urbano conforman la planificación urbana, en términos de Castells (1972), en tanto acción política de los actores con autoridad sobre la ciudad, que incorpora en distinta medida instancias de participación de la sociedad civil. En contextos de mayor autoritarismo, hay una mayor centralización técnica e ideológica en las acciones sobre la ciudad y menor participación de las comunidades.

Es interesante el análisis estructural que Neira (2004) hace al respecto, este autor propone una matriz de distinción para el cambio urbano: por la decisión de autoridades, por acuerdos consensuados o por la suma de acciones múltiples no consensuadas; con la incorporación de enunciados teórico-técnicos, o en ausencia de estos; donde el mejor resultado (ideal) en términos funcionales y técnicos se obtendría a través de la combinación de normas consensuadas y de enunciados teóricos pertinentes. Esta mirada permite analizar el espacio urbano en su proceso de estructuración morfológico-simbólica, comprendiendo la decisión técnica del arquitecto o urbanista, dentro del marco de la acción social, como un actor más, junto con la institucionalidad, el mercado y la sociedad civil.

Ahora, desde la acción institucional se imprimen sobre el espacio determinadas representaciones, con una visión ideológica y técnica, para la construcción de un sentido a través del monumento. Esta acción de enunciación, en términos de Achugar (2003), condensa la memoria y el sentido que se busca proyectar y hacer perdurar.
Carrión plantea que el sentido asignado al monumento en la ilustración, que rememora el patriotismo a través de estatuas de personajes "notables" y ejemplificadores, ha sido resignificado, mediante la reinterpretación de los monumentos, en función de los nuevos y emergentes sistemas de valores. Los símbolos del consumo y la propaganda comercial, por ejemplo, asumen actualmente gran relevancia y visibilidad en el espacio público. En este contexto, Carrión (2008) reivindica para el centro histórico en América Latina la importancia de que el arte "construya su continente y al hacerlo produzca espacio público” (2008, p. 95)1', entregando significación a la ciudad histórica.

También en relación con la acción desde la sociedad civil frente a las representaciones impuestas desde la institucionalidad, se plantea que "el espacio es siempre discutido en su uso y, por ende, nunca puede ser completamente apropiado por los poderes y discursos dominantes" (Salcedo, 2002, p. 14). En este sentido, el espacio público contemporáneo, al acoger la manifestación social, se constituye también como espacio de disputa, pues como señala Aledo, "los actores sociales no aceptan de forma pasiva los mensajes emanados a través de las formas urbanas y arquitectónicas”. La capacidad de resistencia y acción, mediante el desarrollo de estrategias alternativas de uso, es también parte del proceso de construcción del espacio (2000, p. 42).

Puntualmente respecto de la ciudadanía, o de grupos que encuentran en el espacio público un escenario de expresión política y cultural, Borja (2003) revindica la función de este como "escenario de representación”, donde desde el ágora se relata la historia de la ciudad. El espacio público en esta esfera entonces cumple un rol político, acogiendo la manifestación de la soberanía popular, como la definiría Gabriel Salazar (2003), basada en la deliberación del pueblo en el ágora o foro, territorializada en la plaza central, cuya acción soberana contrastaría con la actual presencia deshistorizada de transeúntes, gente de paso o turistas, desconectados de la identidad histórica del lugar.

1 Continente entendido como el entorno del monumento artístico. 
Ahora bien, según Salazar la diversidad por sí misma no asegura construcción de ciudadanía, sobre todo cuando el uso del espacio público no incluye la posibilidad real de que las comunidades se expresen políticamente y ejerzan así su soberanía popular. Este punto es central para el análisis del caso de estudio, entendiendo que la plaza Dignidad tiene un elemento de expresión popular que no se observa en otros espacios públicos centrales de la ciudad de Santiago, como la plaza de Armas o la plaza de la Constitución. Para Salazar, de hecho, los espacios tradicionales han sido despojados de los atributos que permiten el ejercicio de la soberanía popular, al haberse trasladado los ejes de la acción política a las instituciones que concentran el poder y sus edificios, $\mathrm{y}$ al periferizarse las formas de expresión popular, fenómeno definido como desmembramiento del ágora.

\section{Lo festivo}

Las expresiones festivas forman parte también de la soberanía popular y en Chile han sido excluidas de los espacios públicos centrales desde el período poscolonial, diseminándose estos "vestigios de esa vieja dignidad cívica" hacia diversos territorios, bajo múltiples formas (Salazar, 2003, p. 28). También según Borja (2003, p. 122) el espacio público cumple un rol como espacio ciudadano cuando recibe la expresión festiva, en fiestas "de las diferencias" como carnavales, fiestas, reclamos, o protesta que, en tanto manifestaciones de ciudadanía, serían solo posibles en el espacio público.

En la misma línea, desde Lefebvre (1968, p. 124), la expresión festiva forma parte de "necesidades sociales con fundamento antropológico", que comúnmente no son cubiertas en la planificación institucional de las ciudades, centradas en el valor de cambio o el beneficio. Aquellas necesidades se vinculan con la actividad creadora, de obra, de información y lúdicas, y requieren de lugares de encuentro, donde el elemento del "cambio" es más importante que la función utilitaria.

El espacio público es entonces, en relación con lo festivo, escenario de la satisfacción de necesidades urbanas que van más allá de lo individual, que configuran el despliegue de la imaginación y la creatividad, de manera que es a la vez el lugar de la fiesta, del símbolo, del juego, del monumento (Segovia y Oviedo, 2000) y, por lo mismo, espacio de identificación colectiva.

Para Orozco (2018), quien analiza el caso de la plaza Baquedano en Santiago, los eventos con carácter simbólico en el espacio urbano se constituyen como referentes de la cultura local o nacional y, por tanto, pueden ser considerados como fundamento de un patrimonio territorial definido como memoria colectiva, construida en relación con un espacio y vinculada con un legado social, cultural o natural (Orozco, 2020). Lo festivo en el espacio público entonces forma parte de la construcción simbólica del espacio y, por tanto, su presencia espontánea y simultánea a la expresión política, en determinados lugares centrales de la ciudad y no en otros, da cuenta de cómo se territorializa lo público.

A partir del proceso de movilización social desde octubre de 2019 se hace más evidente en la opinión pública la territorialización de la expresión social en el espacio de plaza Italia renombrado plaza Dignidad, proceso acompañado de un conjunto de cambios físicos, pero con carga simbólica, como la eliminación de las rejas, la instalación de imágenes, objetos y rayados sobre el monumento de Baquedano, la instalación de tótems vinculados con los pueblos originarios, la destrucción de la estación del metro, y la instalación de una dinámica de interacción cotidiana de uso festivo del espacio, donde se mezcla la protesta, la fiesta y la expresión escénica y artística.

\section{Metodología}

En términos de la mirada de interpretación del caso de estudio, este artículo busca abrir una línea de análisis desde la historia cultural de la ciudad, la sociología urbana y los estudios urbanos teniendo en cuenta la gran cantidad de trabajos ya existentes sobre este lugar emblemático, muchos de los cuales lo enfrentan desde la descripción periodística e historiográfica.

Es interesante al respecto incorporar la relación entre morfología y representación, que ha sido ya 
abordada por Ángel Rama (1998), al plantear que la ciudad latinoamericana se funda y transforma desde una representación simbólica desde un lenguaje. El analista por su parte también impondría representaciones en la comprensión del fenómeno de la ciudad, interpretando morfología e historia, desde su visión global de otras ciudades, en el contexto de la sociedad de la información. Desde Gorelik (2018), la relación entre morfología e historia en el estudio de la historia cultural de la ciudad requiere hacerse cargo de la multitud de enfoques y de disciplinas que enfrentan el problema de la ciudad, pues no habrá un único método para el análisis.

En cuanto al punto de vista de la estructuración urbana que constituye, desde una perspectiva histórica, el complejo morfológico y cultural en lento, pero constante cambio, este debe tener en cuenta los proceso sociales y simbólicos en juego en el contexto de la ciudad. Para el análisis del proceso de estructuración y la reconstrucción de la memoria del lugar es útil la visión acerca de las distintas representaciones de la ciudad. Desde la sociología y la antropología, podemos abordar las diferentes representaciones o significados como distintas "ciudades" que, traducidas en distintas denominaciones (Italia, Baquedano, Dignidad) y procesos de enunciación, se enfrentan, contradicen o complementan el espacio público y su estructuración.

En este sentido, es importante para la interpretación del caso incorporar la discusión interdisciplinaria en torno al espacio público en cuanto escenario de diversidad y de expresión social y política, pero también festivo, así como también los procesos de enunciación en la ciudad a través de la instalación de monumentos, como expresión discursiva institucional, y las transformaciones de los espacios públicos en la modernidad y posmodernidad como respuesta a la imposición autoritaria de símbolos sobre la ciudad.

En cuanto al análisis del caso, este se presenta en torno a tres focos de atención. En primer lugar, analizando plaza Italia desde su morfología en cuanto al diseño y la intervención del espacio, y tomando como referencia las visiones teóricas o ideológicas presentes en dichos proyectos como acciones de enunciación. La comprensión de este proceso requiere considerar distintas variables en torno a la estructuración de un espacio público monumental de carácter cívico, pero que además se constituye históricamente como lugar de expresión política y festiva. En dicho empeño se confrontan las variables observadas en plaza Italia, con otros casos de espacios públicos de manifestación y fiesta, como Piazza del Popolo en Roma y Maidan o plaza de la Independencia en Kiev, así como también el ejemplo de la Königplatz en Berlín, referencia interesante respecto del análisis histórico del diseño y las visiones filosóficas en la conformación morfológica del espacio de plaza Italia.

Luego se analiza el caso desde las dimensiones de espacio público y flujo, incorporando la revisión de fotografías e imágenes aéreas, para dos cortes históricos: un momento de consolidación del diseño original de plaza Italia, en la década de 1960, y un momento actual basado en el diseño posterior a 2004 y que se establece luego de la construcción del metro en 1977 y la implantación del Transantiago. Este análisis nos permite contextualizar en términos urbanos, la estructuración simbólica de plaza Italia durante el siglo XX.

Luego de la descripción detallada del caso, se realiza una discusión de los conceptos y variables incorporadas para aproximarnos al fenómeno de plaza Dignidad. Para esto partimos dando cuenta del proceso de estructuración de plaza Italia, lugar arraigado en los discursos sobre la ciudad durante todo el siglo XX, para acceder en la reflexión final, al tema de la conformación de plaza Dignidad y observar cómo esta dialoga o se enfrenta con las representaciones históricas e institucionales de plaza Italia y plaza Baquedano.

\section{Resultados}

\section{Plaza Italia y sus transformaciones desde 1928}

Si bien fue el Monumento al Genio de la Libertad homenaje de la colonia italiana e instalado en 1910-el que le da el nombre de plaza Italia al lugar, la conformación 
Figura 1

Plaza Italia, con el monumento de Baquedano en el centro, 1934

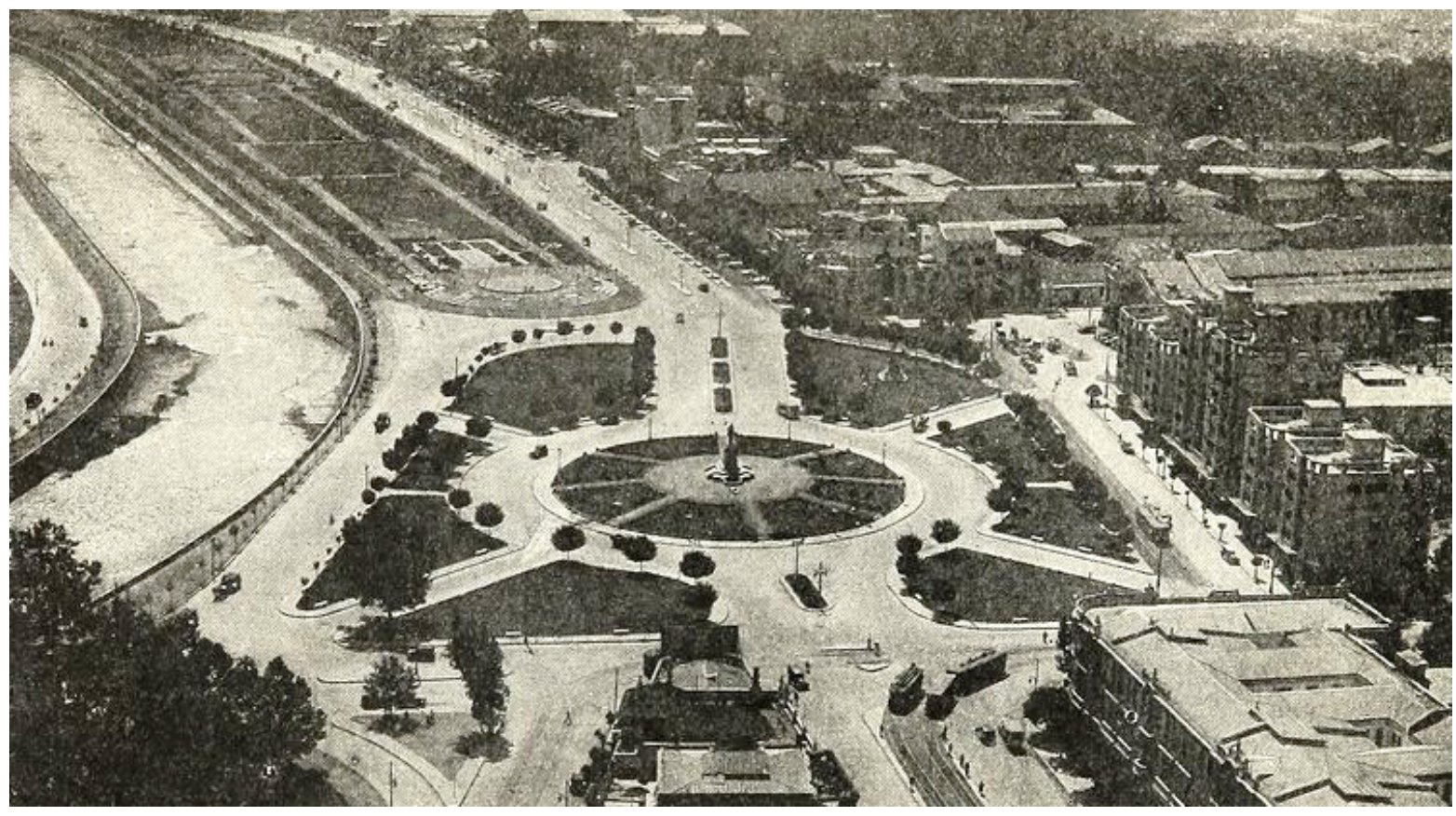

Nota. Memoria Chilena.

definitiva del conjunto urbano durante el siglo XX ubicó a Manuel Baquedano en el centro del espacio público. Su estatua fue instalada durante la conmemoración de los cincuenta años de la guerra del Pacífico, un 18 de septiembre de 1928, de manera que a este lugar emblemático se le asignó un simbolismo republicano, representativo del orden y del triunfo militar del ejército chileno ${ }^{2}$. La acción enunciativa que le entrega un carácter cívico y nacional también tiene un sentido moralizador, pues al conmemorar los cincuenta años de la guerra reconoce también la "valentía" y la entrega por la patria, valores representados por la presencia de los veteranos en la inauguración.

Respecto del espacio público en sí mismo, hay una acción deliberada desde el Estado de darle un rol protagonista a Baquedano. Tempranamente entonces, en este espacio se instala la disputa analizada por Salcedo (2002), pues desde la institucionalidad se impone una significación a este espacio central sin imaginar la multiplicidad de significados y roles que iría adquiriendo para la sociedad durante el siglo XX. Considerando también las reflexiones de Salazar (2003), esta primera acción de instalación de
Baquedano como el emblema de este espacio central, limita la participación y soberanía popular sobre este lugar, imponiendo de plano el carácter de "plaza del orden”. Los análisis posteriores confrontarán el significado impuesto por la acción enunciativa de instalación del monumento a Baquedano en el centro de plaza Italia, con las características urbanas del espacio y con la significación popular que se configura durante el siglo XX hasta nuestros días.

La presencia de Baquedano tiene además una gran significancia política, pues el triunfo bélico representa la consolidación del proceso de territorialización (Metzeltin, 2011, p. 244) fundamental en la conformación del Estado nación: "Desde la constitución del nuevo Estado de Chile, los políticos cuidan la integridad territorial, anclándola en las constituciones”. La anexión del norte grande no solo consolida el territorio nacional, sino que además constituye el factor central de la independencia económica del país.

Una referencia interesante del diseño urbano y la victoria militar, tanto por el conjunto paisajístico como por el

2 Diversas referencias describen las fechas de instalación y modificación de este espacio. Con más detalle lo hace el sitio URBATORIUM, blog de historia urbana de Chile. Ver https://urbatorium.blogspot.com/2012/08/el-origen-del-plaza-italia-para-arriba.html. 


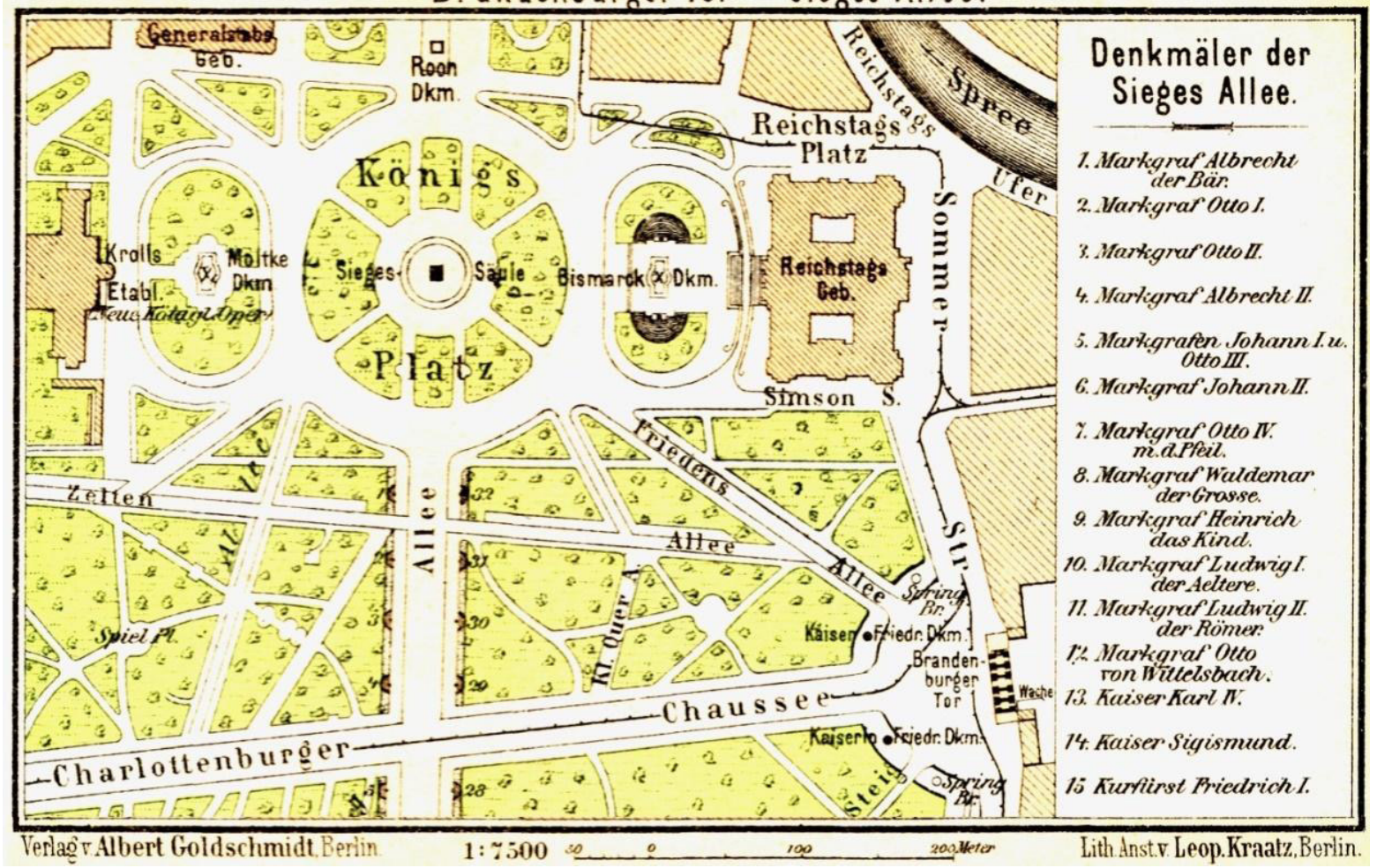

Nota. Anst y Kraatz, 1902.

monumento, es la Königsplatz (plaza del Rey), hoy plaza de la República, en Berlín, donde en su espacio central se ubicaba la Columna de la Victoria, erigida en homenaje a los triunfos de Prusia en diversas guerras durante el siglo XIX. Fue el primer monumento "nacional" del imperio alemán (Brendgens \& König, 2003, p. 188) (Figura 2).

Algunas diferencias con plaza Italia son que el monumento de la Victoria en Berlín se emplazaba en el centro de un conjunto de carácter cívico, frente al palacio de gobierno y adyacente al principal parque de la ciudad. Además, la rotonda que se diseña no forma parte de ejes estructurantes y, por tanto, el flujo no afecta el carácter de espacio público del conjunto. En el caso de Berlín, este barrio cívico forma parte de un parque, mientras que, en el caso de Santiago, el monumento institucional tiene un entorno de menor implicancia política y forma parte de un punto neurálgico de encuentro y flujo y, por tanto, es muy posible que estas dos funciones entren en contradicción. Lo anterior implica que Königplatz constituye una intervención más coherente de conjunto cívico-político, como lo puede ser plaza Bulnes en Santiago.

\section{Diseño del espacio monumental/ institucional}

El diseño original plaza Italia ya descrito vincula una gran plaza y una rotonda rodeada de espacios verdes. En cierta forma el espacio es diseñado para intentar complementar dos funciones principales: la de espacio público central simbólico y la de espacio de flujo vehicular.

En la política urbana de Santiago, a partir de la década de 1920, está presente la intención de generar ciertos espacios de escala monumental, uno de cuyos ejemplos fue hasta cierto punto el conjunto de plaza Italia. Además de los elementos simbólicos mencionados en cuanto la construcción de una idea de nación, hay en el diseño mismo de la plaza y su entorno paisajístico una referencia a la Grand Manner, línea de pensamiento en el arte y la arquitectura y que tiene su período de apogeo en los siglos XVII y XVIII, pero cuya injerencia permanece hasta principios del siglo XX. Esta tradición impone una forma de emplazar los monumentos y estatuas con sentido ceremonial, en 
vías relevantes con valor simbólico y al interior de plazas (Kostof, 1991).

Un aspecto característico de esta forma de diseño, relevante para este análisis, es la conformación axial de los monumentos heroicos ${ }^{3}$. La plaza de la República en Berlín, descrita anteriormente, es diseñada bajo este patrón al formar un espacio concéntrico. La imposición de las vías rectas y las diagonales por sobre la ciudad existente tiene relación con el Grand Manner, así como su origen en el barroco, y como concepto, formó parte del proyecto de Karl Brunner de 1931, para la intervención del barrio cívico de Santiago y proyección del paseo Bulnes (Vergara, 2011).

Es interesante agregar que las intervenciones de este tipo buscaban ampliar las vías principales de la ciudad y proyectar avenidas rectas como un modo de control social, pues se consideraba que las calles estrechas eran un peligro, no solo por la inseguridad pública sino también por posibles riesgos de desobediencia civil. Kostof (1991) también señala explícitamente que, de hecho, este tipo de intervenciones se realizaron en general bajo estados centralistas y autoritarios.

\section{Factores en la conformación de un espacio monumental, entre lo político y lo festivo}

Respecto de la conformación del conjunto plaza Italia, además del diseño de la plaza misma, otros elementos resultan interesantes y dan cuenta de un espacio monumental, posibilitado en primer lugar por la canalización del río Mapocho, lo que permite disponer de un amplio espacio para planificar el conjunto y proyectar el parque Balmaceda hacia el oriente.

Un primer factor de la monumentalidad es la extensión y amplitud del espacio público, cuyo centro pasa a ser la plaza Baquedano, y que interconecta el parque Forestal, el parque Balmaceda una vez concluido, y el parque
Bustamante, luego de la demolición de la estación Pirque en 1945 (Figura 1). El carácter abierto y amplio del lugar $\mathrm{y}$ el encuentro de tres parques en un espacio central es excéntrico en la ciudad de Santiago y, por tanto, es ineludible la potencialidad del conjunto en cuanto a su función recreativa y de encuentro.

Un segundo factor tiene que ver con el emplazamiento de diversos monumentos de personajes de la historia política de Chile, aunque con variado simbolismo. Junto con la instalación de Baquedano en 1928 y la reubicación de la estatua del Genio de la Libertad fue importante la construcción del parque Balmaceda entre 1941 y 1947, desde el obelisco hacia el oriente, monumento que se inició en 1935 y concluyó en 1949. Por otro lado, en la entrada al parque Bustamante se instaló en 1947 la estatua definitiva de Manuel Rodríguez. La fuente de Mercurio y Victoria junto a un minero y a una mujer criolla, instalada para el centenario en 1912, da la entrada al parque Forestal ${ }^{4}$.

Estos monumentos conforman un conjunto bastante diverso en términos simbólicos. Son representativos de la construcción del Estado nación posguerra del Pacífico, de la independencia, de comunidades de inmigrantes y de símbolos populares, lo cual da cuenta de que el conjunto, ya a mediados del siglo XX, se consolide como un espacio de carácter cívico, histórico, pero también laico. De hecho, en el entorno de plaza Italia no hay edificios religiosos a diferencia de la gran mayoría de las plazas centrales de escala urbana en Chile.

El simbolismo "cívico" que a mediados del siglo XX se consolida en torno a Plaza Italia refuerza la función recreativa, pues el espacio es digno de ser visitado y recorrido, al contener una parte importante de la historia nacional, monumentos de calidad y espacios verdes bien mantenidos. El carácter cívico, lo es solo de manera exterior, pues la organización del espacio no contempla instancias de deliberación y, por tanto,

3 Axial en el sentido de que desde el eje o vértice central se proyectan distintos vectores formando una estrella simétrica, o una cruz atravesada por dos diagonales.

4 Conocida popularmente como la fuente Alemana. 


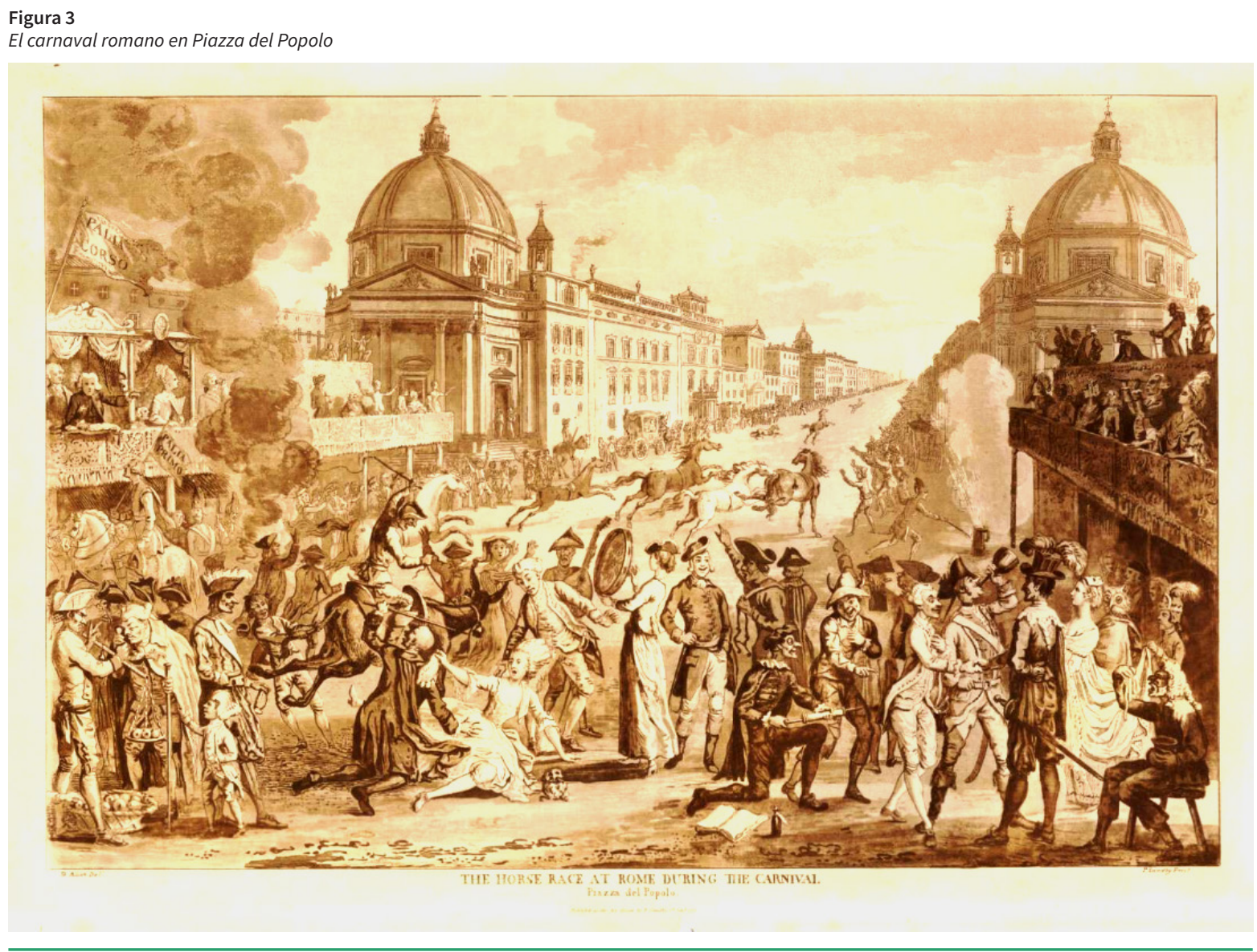

Nota. Sandby, 1781.

este espacio público se diseña con elementos de ágora, pero esta no necesariamente se realiza en términos de Arendt, como espacio público de libertad y expresión política de lo diverso (Gorelik, 2008).

El espacio se conforma permitiendo una vista panorámica de todo el entorno construido y del borde del río Mapocho. Esta amplitud de visión produce una sensación distinta respecto de otros lugares de la ciudad, incluso la plaza de Armas. Salazar (2003) relaciona la apertura del espacio con la posibilidad del ejercicio de la soberanía, pues aquella permite la diversidad de actividades "ciudadanas". El zócalo abierto de la plaza de Armas, con anterioridad a 1850, fue escenario de actividades, desde el cabildo, los ejercicios de la guardia cívica, a los juegos y divertimentos festivos en época de carnaval (Salazar, 2003).

Senabre describe la intervención para regresar a la plaza mayor de Salamanca a su condición original de zócalo: "La Plaza mostraba, así, por primera vez, y con la ayuda del vacío como aliado singular, el segundo valor que pocos habían descubierto: una atmósfera de pública privacidad" (2008, p. 200). El valor de la apertura en los espacios públicos, como tercer factor de la monumentalidad, motivó el regreso a las plazas vacías en la segunda mitad del siglo XX, no solo en España sino también en América Latina, cuyo ejemplo paradigmático por su extensión es el zócalo de ciudad de México.

Dos espacios públicos que se considerarán en el análisis también incorporaron al menos en un período histórico la amplitud o apertura del espacio como factor de la centralidad y de la expresión festiva y política de la comunidad urbana: la plaza de la Independencia en Kiev (Figura 4) y la Piazza del Popolo en Roma (Figura 3). En el primer caso, en el período de posguerra la intervención sobre la plaza abrió el espacio instalándola como un centro ideológico que permitiera la presencia masiva, desfiles y una fuente de agua (Oliynyk, 2015). El espacio fue de esta forma valorado por la comunidad y adquirió también un rol recreativo. 


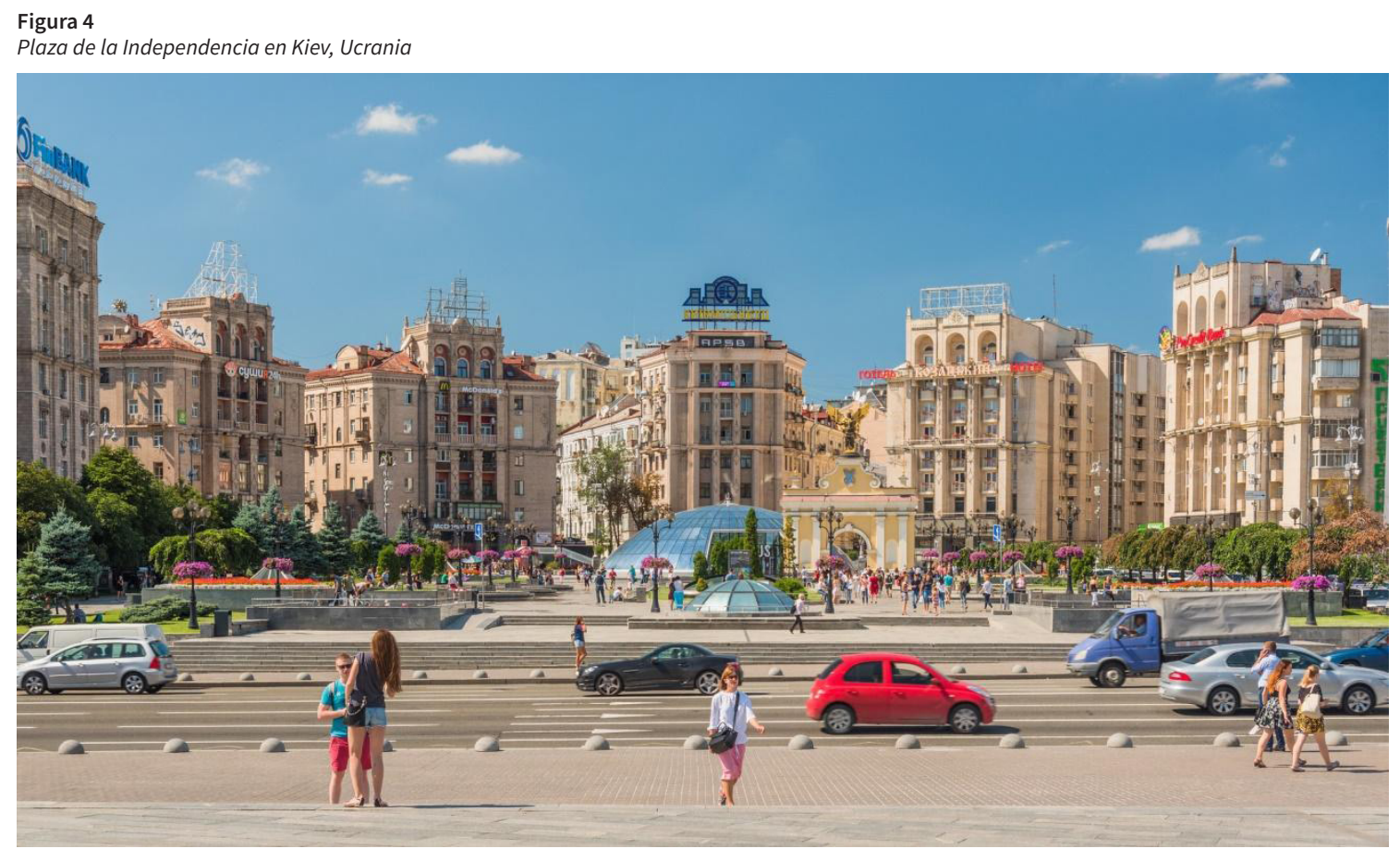

Nota. Lynch, 2017

En el caso de Roma, Baeta (2017, p. 219) plantea que las intervenciones viales de carácter moderno en Piazza del Popolo en el siglo XVI potenciaron la invasión de las "aventuras escenográficas" derivadas de la exaltación de la naciente cultura barroca. La conformación del conjunto, con los elementos no diseñados, como la entrada norte a la ciudad, el trívium o tridente de tres vías hacia el sur y el espacio abierto, se completa con las intervenciones de las dos iglesias y el obelisco, como "dispositivo teatral" del drama barroco escenificado en el corazón de la ciudad, a la cual se accede al entrar por la puerta del Popolo. Este emblemático espacio sería posteriormente uno de los principales escenarios festivos en los festejos del carnaval romano, pero también de reuniones y manifestaciones políticas hasta la actualidad.

El cuarto elemento en el conjunto monumental de estudio es la simetría, la cual no necesita ser perfecta matemáticamente, sino que debe ser interpretada, desde la percepción subjetiva, como parte de un todo, para ser "aprovechada por la mente como obra abierta" (Baeta, 2017, p. 229). Este aspecto del barroco, que implica una manera de concebir el acceso a la obra artística, llevado a la ciudad, también está presente en plaza de la Independencia en Kiev en Ucrania.
El entorno del ágora de la plaza se compone de edificios de distintos momentos del siglo $\mathrm{XX}$, pero visualmente se percibe como simétrico, armónico y bastante representativo estéticamente de la arquitectura monumental soviética (Oliynyk, 2015). Al extremo opuesto de la plaza, se ubica el monumento de la Independencia y la Academia Nacional de Música Petro Tchaikovsky, por lo cual se trata de un espacio de fuerte carga histórica y simbólica, y que además se instala como escenario de manifestaciones sociales, como las protestas pro europeas que asumieron el nombre de Revolución de la Dignidad en 2014, aunque con bases políticas muy distintas que las que han sustentado la protesta social actual en Chile. Este espacio en el siglo XIX contenía un mercado popular abierto y también actividades recreativas, circenses y bohemias, por tanto, han coexistido históricamente en este lugar lo político y lo festivo.

La simetría como elemento constitutivo de un conjunto monumental también se aplica sobre el espacio de plaza Italia durante el siglo XX, si bien no desde la planificación centralizada como en el caso de Kiev, ni desde los gobiernos pontificios y organizaciones de la Roma barroca (en las iglesias gemelas de Piazza del Popolo), sino desde distintas y separadas acciones privadas y estatales, especialmente en el diseño y construcción de los edificios Turri entre 1929 y 1931 (Figura 5). 
Figura 5

Edificios Turri frente a Plaza Baquedano

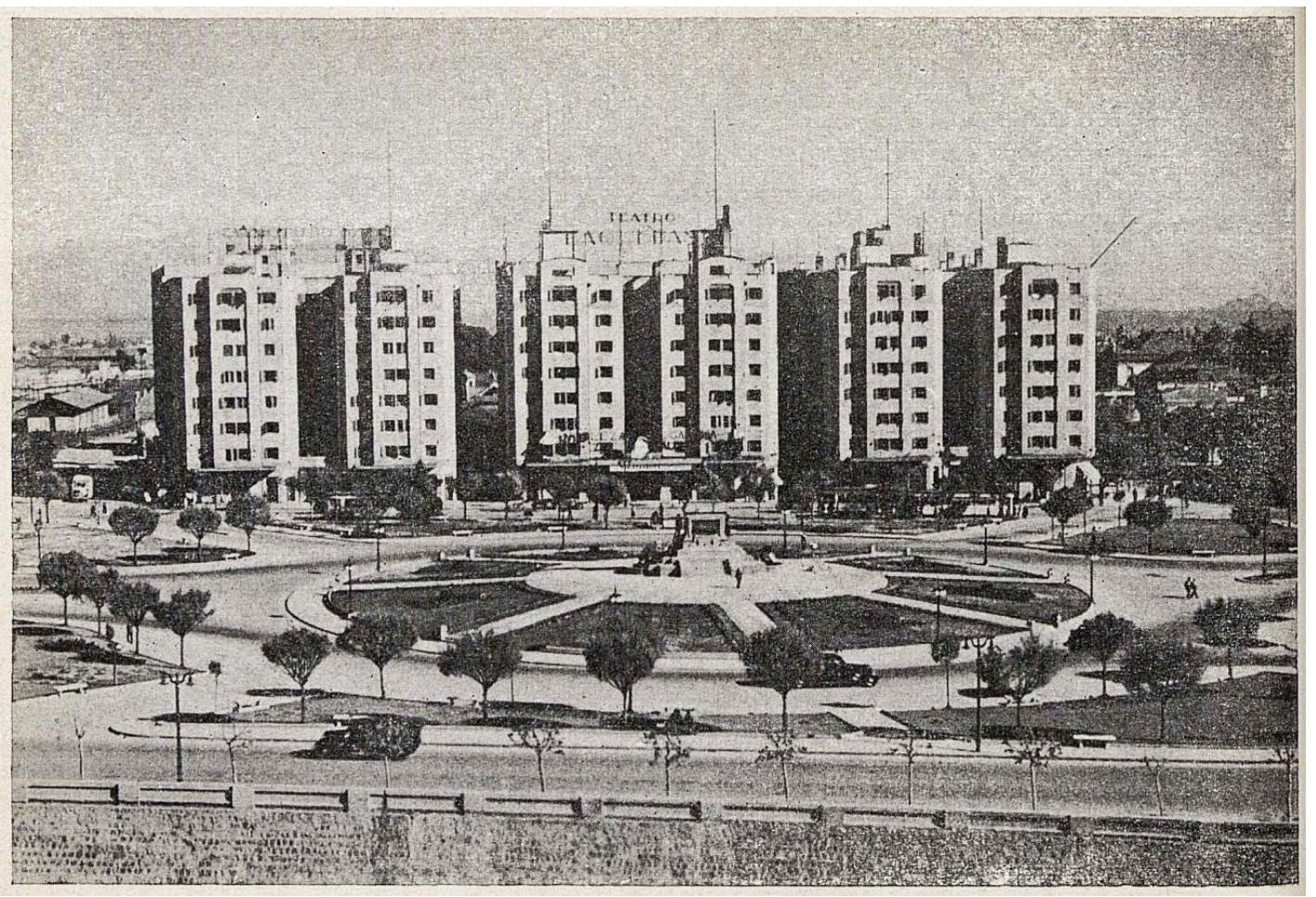

Nota. Autor Desconocido, 1938

Si bien en la conformación del conjunto de plaza Italia no hay una única visión, sino diversas miradas y acciones en el tiempo, para Nassau (2012) estas constituyen modificaciones intencionales del paisaje urbano y, por tanto, parte de un diseño. Ahora, a diferencia de los ejemplos mencionados antes, en el caso de plaza Italia el edificio que sobresale sobre el panorama urbano y que entrega la simetría al conjunto monumental solo puede ser apreciado de frente ubicándose en medio del conjunto, en plaza Baquedano, pero para la mayor parte de los transeúntes o visitantes del espacio, el edificio acompaña la vista lateral al pasar por el eje estructurante AlamedaProvidencia. Así, la mayor experiencia del espacio como escenario, como quinto factor, se logra desde el centro, desde donde se aprecia no solo el entorno construido sino además la extensa vista hacia los parques cercanos y el cerro San Cristóbal en el fondo.

El conjunto entonces incorpora elementos naturales y no solo construidos. Si es representativo de una identidad nacional, esta contiene también los atributos naturales y ambientales. La instalación del teatro Baquedano dentro de los edificios Turri complementa el factor escénico que podríamos describir como monumental, recreativo, histórico y teatral. De esta forma el emplazamiento del teatro aporta a la centralidad cultural del lugar, potenciando el encuentro de personas, además del flujo.

\section{Relación entre espacio público y flujo. La plaza diseñada vs. la plaza intervenida}

El análisis en términos urbanos del caso de estudio se organiza en función de los momentos de plaza Italia señalados anteriormente: aquel previo a la construcción del metro, como diseño original desde 1928, y el actual. En el caso analizado conviven las dimensiones de espacio público y la de flujos de transporte, pues la plaza contiene una rotonda, que a diferencia de Königplatz, se encuentra en un punto neurálgico de la ciudad, con un importante tráfico vehicular.

En cuanto a la dimensión de espacio público el diseño original contemplaba una gran plaza verde, con veredas caminables, y un espacio central con un monumento de relevancia urbana y nacional. El conjunto además conecta distintos parques: el parque Balmaceda hacia el oriente, el parque Forestal hacia el poniente y el parque Bustamante al sur, luego de la demolición de la estación 
Figura 6

Análisis histórico plaza Italia y entorno

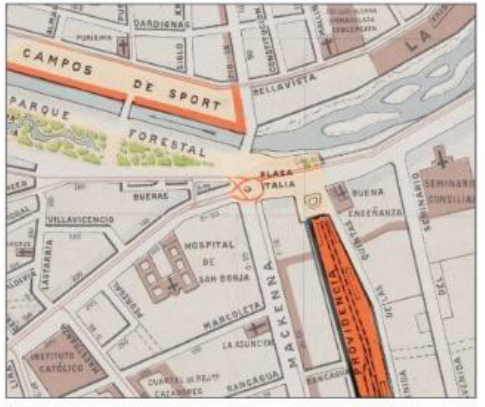

Lámina 1. Plano 1911. Nicanor Boloña. Fuente: Archivo Visual, UC.

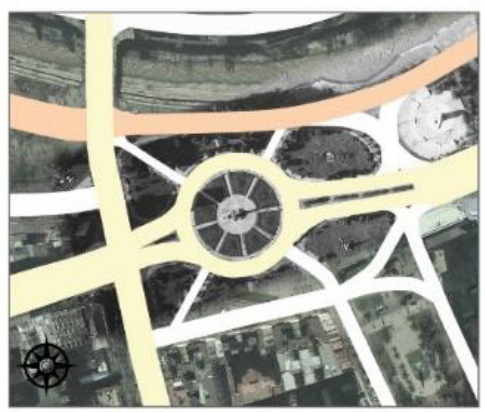

Lámina 2. Vias 1964. Elaboración propia.
La lamina 1 muestra el entorno urbano de Plaza Italia, la presencia de la Estación de trenes Providencia, después llamada Estación Pirque. Se observa el Parque Forestal y terrenos deportivos que luego formarían el parque Gómez Rojas.

En la lámina 2 se observa el sector de Plaza Italia y la estructura vial del proyecto de la década de 1920, donde Plaza Baquedano constituye una rotonda con múltiples accesos.

Las fotografías permiten apreciar como el espacio público de Plaza Italia es caminable y forma parte del sistema de parques $y$ monumentos cercanos.

El montaje de fotografías aereas permite apreciar más en detalle la conformación del conjunto de plaza Italia y la localización del monumento Genio de la Libertad luego de la instalación del monumento a Baquedano, en el espacio central.

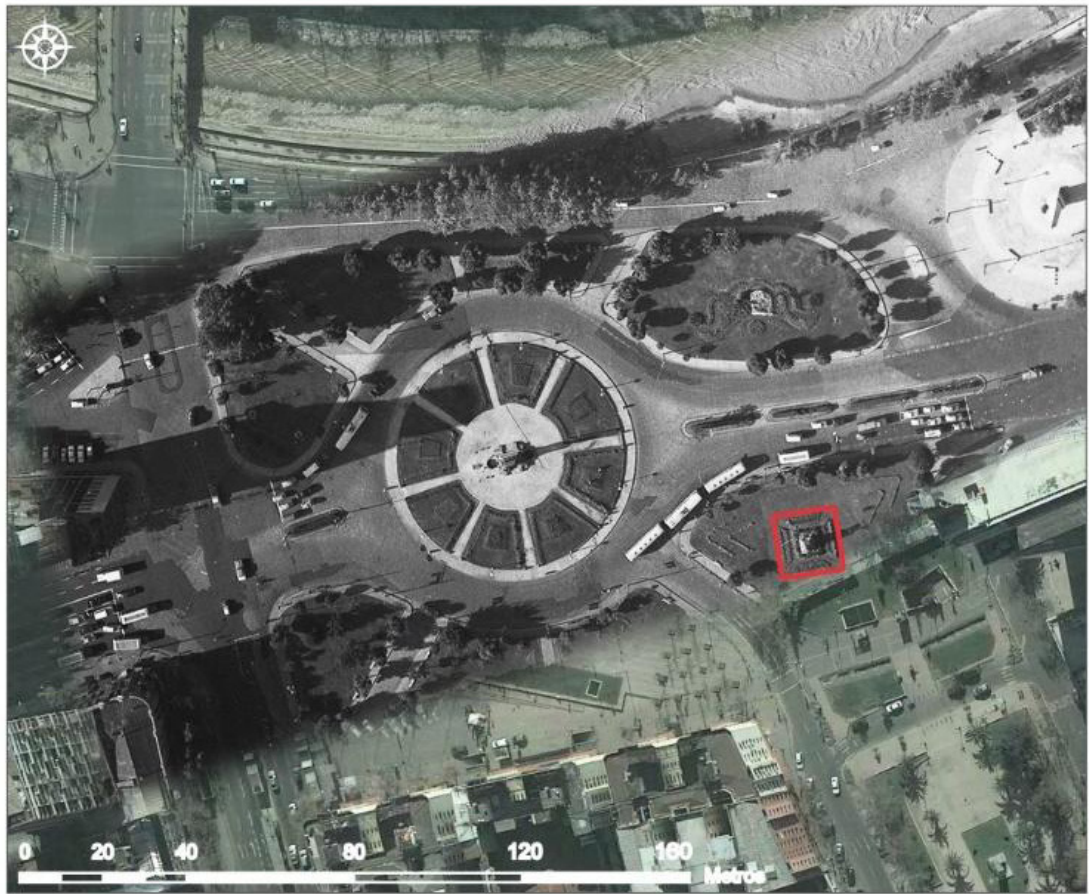

Foto 2. Década 1960. Diapositiva Riefschneider Fuente: Fundación Enterreno.

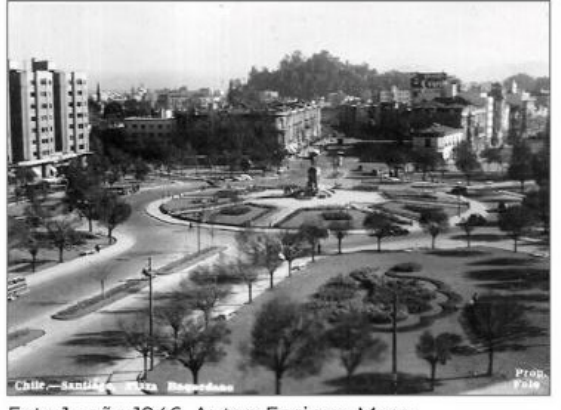

Foto 1. año 1946. Autor: Enrique Mora

Fuente: https://cenfoto.udp.cl Cultura Digital UDP

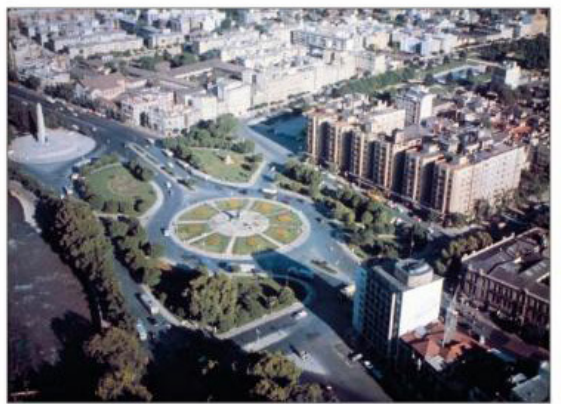

\section{SIMBOLOGIA}

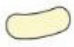

Ejes estructurantes Alameda-Providencia y Vicuña Mackenna

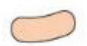

Vias intercomunales actualmente conectadas a autopista

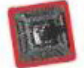

Monumento al

Genio de la Libertad

comunidad italiana

Nota. La fuente original del plano de la Lámina 1, de autoría de Nicanor Boloña, es la Bibliothèque Nationale de France. El Archivo Visual del Centro del Patrimonio Cultural UC, se encuentra en el sitio archivovisual.cl 
Pirque. Al lado norte del río se emplaza el parque Gómez Rojas, cuyos terrenos originalmente se utilizaban para la práctica deportiva. El bajo flujo vehicular en las primeras décadas de la plaza no afectaba en gran medida el acceso peatonal al espacio.

En relación con la dimensión de flujo, el diseño contenía una rotonda con diversos accesos laterales vehiculares, que bordea el monumento a Baquedano. Esta formaba una circunferencia perfecta limitando la velocidad vehicular y con ello también buscaba mantener el carácter de espacio caminable. La presencia de la estación Pirque hasta 1947, potenciaba la centralidad y accesibilidad del espacio, pues sumado a la reciente avenida Vicuña Mackenna, conectaba el centro de la ciudad con la periferia sur.

Tanto la dimensión de espacio público como la de flujo potencian la centralidad de plaza Italia, considerando además la localización neurálgica del lugar. Sin embargo, el crecimiento de la ciudad, el aumento exponencial de la población, los procesos de segregación social y los cambios culturales durante el siglo XX hicieron que estas dos dimensiones entraran en conflicto, presionando las necesidades de flujo a la función de espacio público, lo que se tradujo en intervenciones luego de la construcción del metro.

Camillo Sitte en sus análisis sobre la estructura de los espacios centrales en la ciudad moderna, plantea: "hemos denominado 'plazas' a estos puntos de convergencia de tráfico, aunque no poseen ninguna de las características de las plazas" (2013, p. 63). Como intuye Sitte (2013), la regularidad geométrica impresa en el espacio, interesante estéticamente, no necesariamente tiene efectos concretos en facilitar el uso peatonal. Esta forma de diseño sería resultado de una planificación más focalizada en el tráfico que en los espacios mismos.

Plaza Italia muestra en su diseño original una estructura axial, tanto en el diseño del espacio circular interno, como en las vías vehiculares que surgen del eje de la rotonda (Figura 6). Estas dan origen a pequeñas secciones verdes, o "pequeñas islas de refugio para los peatones", en palabras de Sitte (2013). Por otro lado, sobre el conjunto se proyecta el eje estructurante Alameda-Providencia que lo atraviesa.

Con posterioridad a la construcción del metro diversas intervenciones modificaron el diseño original, limitando la dimensión de espacio público y de encuentro para suplir las necesidades de transporte y conexión: el ensanche de la vía vehicular que quitó terreno a la plaza central, la transformación de las áreas verdes aledañas en espacios verdes no caminables y la disminución de los senderos peatonales en la plaza central.

La instalación del metro Baquedano y, posteriormente, la conexión a la línea 5 del metro potenció aún más el carácter neurálgico del lugar, lo que sumado al aumento exponencial del flujo vehicular por el eje AlamedaProvidencia, modificó fuertemente el funcionamiento original de plaza Italia. A ello se agrega la instalación de la salida del eje Costanera sobre parte del espacio verde original, lo cual dificulta el acceso a la plaza central que se convierte principalmente en un monumento, más que un espacio de encuentro, mientras aumenta la presión vehicular sobre el nodo Alameda-Vicuña Mackenna. La presión que ejerce el flujo dificulta el vínculo entre los parques cercanos y la plaza central, haciéndola más inaccesible a las personas.

A partir de la intervención de 2004, la zona de encuentro se trasladó frente a los edificios Turri y se vinculó a la salida de la estación de metro Baquedano. Este espacio se instaló como un punto de reunión, mientras el resto de las "islas" verdes o caminables en torno a la plaza Baquedano fueron perdiendo importancia y presencia de personas, como aquella al norte, donde se relocalizó la estatua del Genio de la Libertad, el triángulo central al oriente del centro de la rotonda y el angosto sendero que conecta el monumento de Italia con el de Balmaceda.

La intervención que resultó decisiva en la transformación del carácter de espacio público de plaza Italia fue el enrejamiento progresivo del área central con vallas policiales desde 2006, el cual se consolidó luego de las manifestaciones estudiantiles de 2011 (Figura 7 y 8) 
Figura 7

Análisis actual plaza Italia y entorno

PLAZA ITALIA. ESPACIO PÚBLICO CENTRAL, ENTORNO URBANO Y PAISAJÍSTICO.
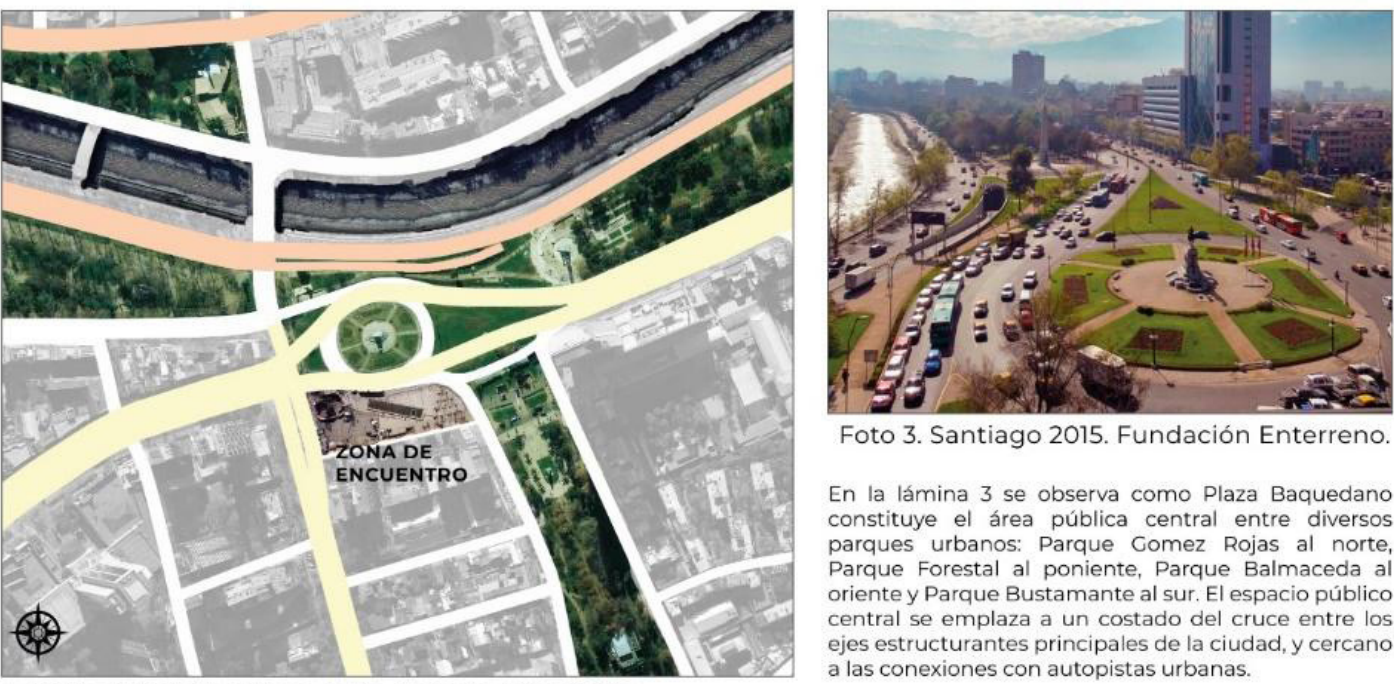

Foto 3. Santiago 2015. Fundación Enterreno.

En la lámina 3 se observa como Plaza Baquedano constituye el área pública central entre diversos parques urbanos: Parque Gomez Rojas al norte Parque Forestal al poniente, Parque Balmaceda al oriente y Parque Bustamante al sur. El espacio público central se emplaza a un costado del cruce entre los ejes estructurantes principales de la ciudad, y cercano a las conexiones con autopistas urbanas.

Lámina 3. Entorno Plaza Italia. Elaboración propia.
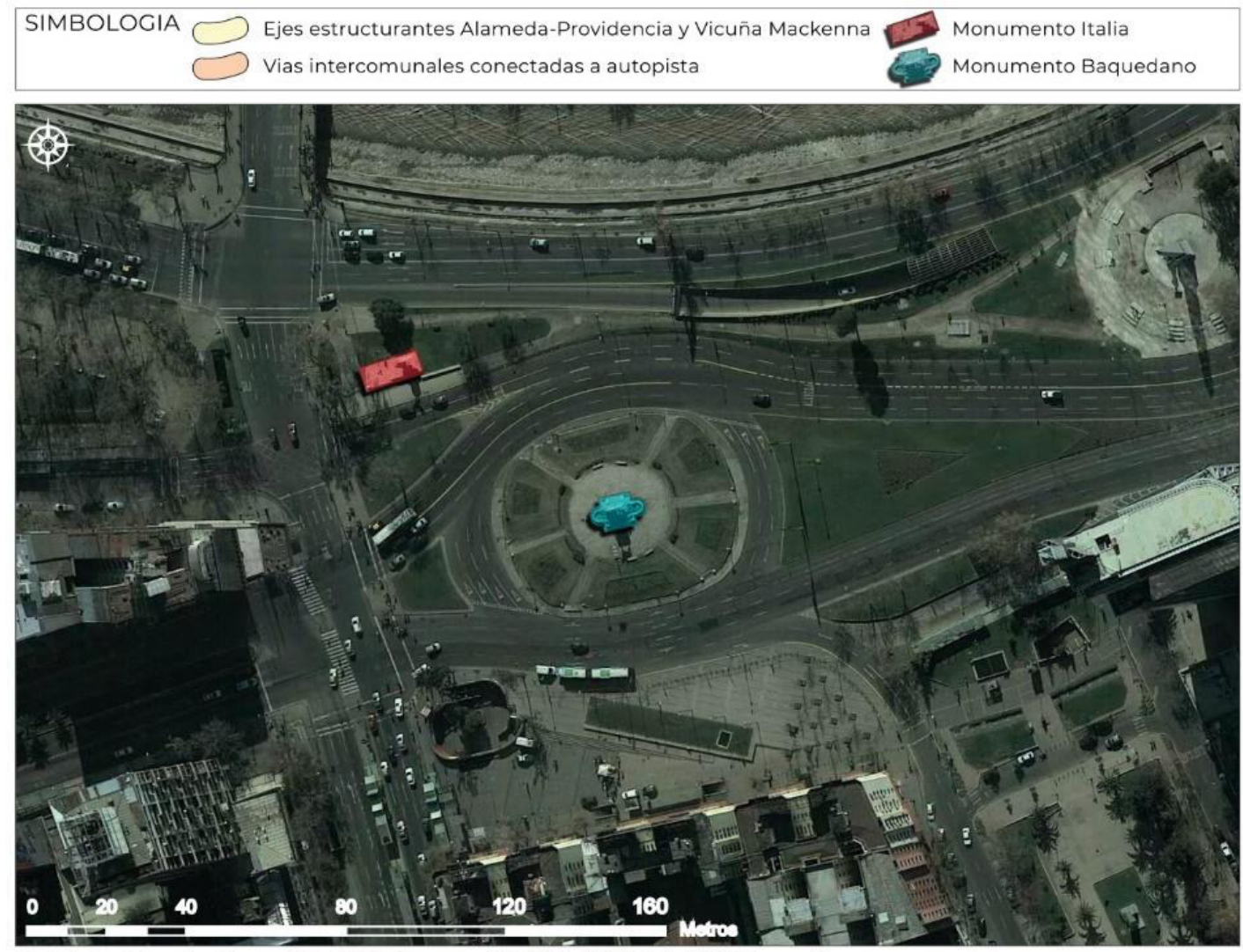

Ortofoto Gran Santiago Año 2012. Fuente: SECTRA. WCS-84, UTM, huso 19 sur 
Figura 8

Plaza Baquedano enrejada

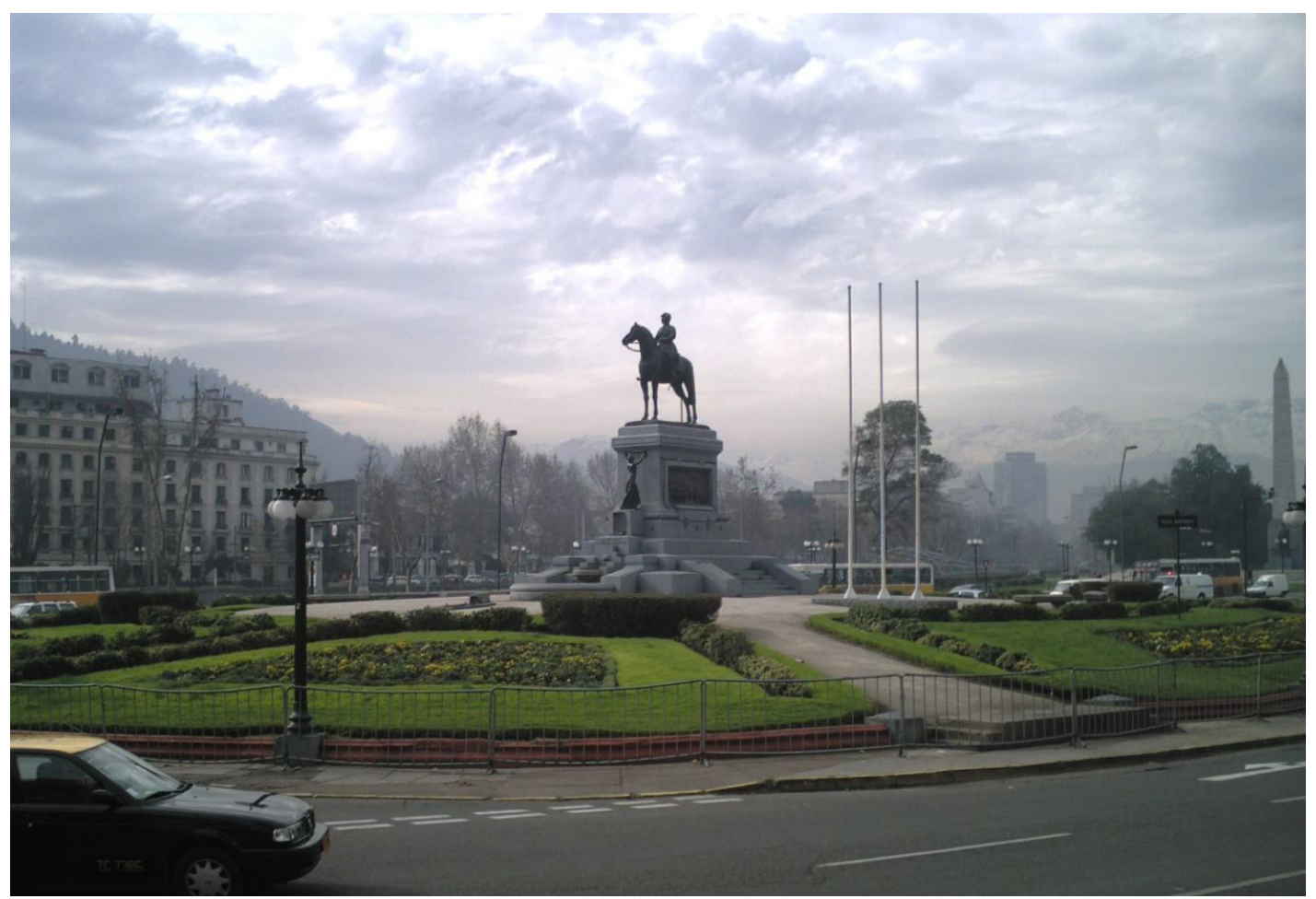

El enrejamiento privilegió el mantenimiento estético del área verde y el monumento de Baquedano, para ser apreciado desde lejos y no visitado, a excepción de momentos excepcionales. Prácticamente todo el resto del área verde en torno a Plaza Baquedano se transformó en espacios verdes poco caminables y residuales en cuanto a su uso público. Esta última imposición institucional sobre el uso del espacio y su sentido revela los procesos descritos de fragmentación y de debilitamiento de lo público reflejado en el espacio urbano, institucionalizándose la desconfianza hacia el encuentro y la diversidad e imponiéndose la homogeneidad y la monofuncionalidad: se llama plaza Baquedano y es un monumento histórico y militar.

El espacio se "personaliza" en la medida en que la dimensión de flujo se impone sobre la de espacio público, impidiendo desde la política la deliberación y, con ello, la construcción de ciudadanía, aun cuando el lugar se encuentra en el imaginario colectivo como punto de festejo desde la celebración del plebiscito de 1988 (Orozco, 2018) y también de protesta desde la dictadura (Rodríguez, 1984).

\section{Conclusiones}

Este artículo se ha enfocado sobre la plaza Italia, pues se considera que son la estructuración urbana y simbólica del espacio durante el siglo XX hasta la fecha, y no solo los eventos del último tiempo, la base de las contradicciones y disputas actuales en torno al concepto de plaza Dignidad.

Los factores descritos para Maidan en Kiev y Piazza del Popolo en Roma, como lugares emblemáticos monumentales y de expresión social, están también presentes en el conjunto de plaza Italia: la conformación de un gran espacio público, la presencia de monumentos de valor simbólico, la simetría estética en el entorno, la apertura o amplitud del espacio y el carácter escénico y teatral. Cobra sentido entonces el concepto de calidad desarrollado por Segovia y Neira (2005), en tanto que plaza Italia en su estructuración histórica posee atributos espaciales para una gran diversidad de actividades y de encuentros. Por tanto, efectivamente la plaza Italia se constituye durante el siglo XX como un conjunto monumental con factores morfológicos característicos de una "plaza del pueblo", o sea como lugar que facilita la deliberación y la creatividad. 
En su conformación simbólica posee atributos que contribuyen a la heterogeneidad social, esto es monumentos laicos con significados históricos y sociales diversos: populares, de comunidades de inmigrantes, cívicos y militares. A su vez la expresión política en el lugar desde la dictadura ha sido principalmente de sectores progresistas, estudiantiles y movimientos de reivindicación social, aun cuando también se han desarrollado allí manifestaciones y reuniones de grupos más conservadores o de derecha.

Por otro lado, en cuanto a la expresión festiva, también ha contenido diversidades: realización de conciertos durante el estallido social, reunión de barras de fútbol y festejos deportivos, punto de encuentro de la vida nocturna y cultural en torno al cine arte, al Centro Cultural Gabriela Mistral, al teatro de la Universidad de Chile, o al barrio bohemio Bellavista, como describen Ossa y Richard (2004). En términos de Orozco (2018), las celebraciones ya forman parte de la memoria colectiva de plaza Italia.

Respecto de las dimensiones de encuentro y flujo, la accesibilidad es una característica, tanto en términos de facilidad, como en cuanto nodo de atracción de personas, pero también en términos de igualdad en las posibilidades de acceso, lo cual permite una diversidad de ocupantes y, por lo tanto, el lugar facilitaría la deliberación social y la construcción de ciudadanía, aunque en términos prácticos haya limitaciones políticas.

No obstante, la estructuración de la plaza Italia, con la centralidad creciente del monumento a Baquedano, entra en contradicción con las representaciones sociales sobre el espacio y el ejercicio efectivo de la deliberación. La potencialidad política y cultural del espacio público encuentra obstáculos producto de la imposición de la representación institucional, sumado esto a la presión de las necesidades de flujo producto del crecimiento urbano de Santiago y el consiguiente deterioro de las áreas verdes y zonas de encuentro.

\section{Contradicción y disputa hacia plaza Dignidad}

Utilizando la matriz de análisis de Neira (2004), en el caso de estudio se superponen y contradicen estructuralmente dos dinámicas culturales: el cambio urbano por decisión de autoridades sin consenso comunicativo (la instalación de Baquedano y la monofuncionalidad de la plaza central), y el cambio urbano por modificaciones acumuladas sin consenso (el nombre plaza Dignidad y los símbolos incorporados al espacio). En otras palabras, el diseño político institucional de 1928, tanto de la morfología del conjunto paisajístico de plaza Italia, como la decisión del protagonismo de Baquedano y los símbolos nacionales, tuvo un carácter autoritario, y limitó las intervenciones desde la sociedad civil.

Lo anterior implica que desde la institucionalidad no fue comprendido el sentido social que históricamente fue adquiriendo plaza Italia y, al contrario, a través de la represión fue progresivamente negado el acceso al espacio y a la manifestación. La "Batalla de plaza Italia” (Fernández, 2013, p. 32) es producto de esta contradicción no resuelta: la expresión política y festiva se realiza en el espacio como una batalla, dada por la búsqueda de la apropiación simbólica y política del espacio público popular. La contradicción y disputa por el espacio además se tradujo durante los meses de movilización social en la transformación del lugar y sus monumentos (Oliva, 2020) y, durante la pandemia, en la restauración parcial, borrado de intervenciones y grafitis y "limpieza" constante del monumento a Baquedano. Esto se tradujo en la intensificación del uso de la fuerza para imponer la monofuncionalidad del espacio y reivindicar la preeminencia de Baquedano, afectando el carácter público del lugar, en cuanto escenario de diversidad y expresión, lo cual da cuenta de la visión autoritaria anteriormente descrita.

Siguiendo a Harvey (2012) en cuanto al derecho de cambiar y reinventar la ciudad, como una forma de ejercicio de poder colectivo por sobre el proceso de urbanización, las intervenciones sobre plaza Italia y la ocupación deliberada del lugar constituyen la incorporación de 
la mirada no institucional y de la diversidad social, en la estructuración urbana del espacio. En esta línea, la denominación popular de plaza Dignidad, como reescritura de los sentidos atribuidos al lugar durante todo el siglo $\mathrm{XX}$, inaugura la conformación efectiva y reafirmación de lo que denominamos "plaza del pueblo", por primera vez desde los discursos de los actores sociales, frente a las determinaciones cívico-jurídicas, en términos de Delgado y Juárez-Salazar (2018).

En la instalación de plaza Dignidad, se observa entonces un cuestionamiento e intentos de intervenir, modificar o destruir el símbolo de Baquedano, como representante del discurso nacional-institucional impuesto durante el siglo XX, pero además está presente la lucha por la ocupación del espacio cada viernes, en una mezcla de protesta, expresión de las demandas sociales y celebración. En la disputa ya instalada la apropiación de plaza Dignidad adquiere un sentido en sí misma, como plantean Caulkins, Fontana, Aracena y Cobos (2020). La ruptura de la hegemonía simbólica institucional abre entonces para plaza Dignidad la posibilidad real de ejercicio de soberanía en términos de Salazar (2003) y, de hecho, desde el lugar se instalan temas y discursos hacia la opinión pública.

Queda entonces pendiente saber cómo se resolverá la contradicción analizada: si se construirá un acuerdo entre las distintas representaciones del lugar, o si se impondrá definitivamente una de las visiones. Está claro de todas formas que plaza Dignidad y sus significados no podrán ser borrados o quitados del lugar y será necesario incorporarlos en futuras intervenciones urbanas.

\section{Referencias bibliográficas}

Achugar, H. (2003). El lugar de la memoria, a propósito de monumentos (motivos y paréntesis). En V. Langland y E. Jelin (Comps.), Monumentos y marcas territoriales (pp. 141-167). Siglo XXI.

Aledo, A. (2000). El significado cultural de la plaza hispanoamericana. El ejemplo de la plaza mayor de Mérida. Tiempos de América, 5(6), 37-47. http://dx.doi. org/10.6035/Tiempos
Anst, L., y Kraatz, L. (1902). Berlín y alrededores [Plano]. Guía de viaje, Griebens. Wikipedia. https://es.wikipedia.org/ wiki/Platz_der_Republik\#/media/Archivo:Berlin_ Siegesallee_Plan_1902.jpg

Azocar, J. (2006). Política chilena de vivienda social: una mirada a su concepto de espacio público en la posmodernidad. Revista INVI, 21(57), 10-43.

Baeta, R. (2017). Cidade barroca na Europa e América Ibérica. EDUFBA, PPGAU.

Borja, J. (2003). La ciudad conquistada. Alianza Editorial.

Borja J. y Muxí, Z. (2003). El espacio público, ciudad y ciudadanía. Electa.

Brendgens, G., \& König, N. (2003). Berlin Architektur: Architekturführer. Jovis.

Carrión, F. (2007). Espacio público: punto de partida para la alteridad. En O. Segovia (Ed.), Espacios públicos y construcción social. Hacia un ejercicio de ciudadanía (pp. 79-97). SUR.

Carrión, F. (2008). Centro histórico: la polisemia del espacio público. Centro-h Revista de la Organización Latinoamericana y del Caribe de Centros Históricos, (2), 89-96. https://www.redalyc.org/articulo. oa?id=115112535008

Castells, M. (1972). Problemas de investigación en sociología urbana. Siglo XXI Argentina Editores.

Caulkins, M., Fontana, M., Aracena, F. y Cobos, M. (2020). Territorios en disputa: la apropiación del espacio urbano tras el estallido social del 18/O. El caso de la plaza de la Dignidad. Persona \& Sociedad, 34(1), 159-183.

Delgado, R. y Juárez-Salazar, M. (2018). Ciudad adentro. Espacio, relato y extimidad en la escritura de la ciudad. URBS. Revista de Estudios Urbanos y Ciencias Sociales, 8(2), 73-84. 
Fernández, R. (2013). El espacio público en disputa: manifestaciones políticas, ciudad y ciudadanía en el Chile actual. Psicoperspectivas: Individuo y Sociedad, 12(2), 28-37. http://dx.doi.org/10.5027/psicoperspectivasVol12-Issue2-fulltext-278

Gorelik, A. (2008). El romance del espacio público. Alteridades, 18(36), 33-45. http://www.scielo.org.mx/pdf/alte/ v18n36/v18n36a4.pdf

Gorelik, A. (2018). La historia es una disciplina muy afortunada, nos ponemos mejor a medida que envejecemos. Ciudad Paz-ando, 7(2), 216-236. https://doi.org/10.14483/ udistrital.jour.cpaz.2014.2.a12

Harvey, D. (2012). Ciudades rebeldes. Del derecho a la ciudad a la revolución urbana. Akal.

Jacobs, J. (2011). Muerte y vida de las grandes ciudades. Península.

Kostof, S. (1991). The City Shaped: Urban Patterns and Meanings Through History. Little, Brown and Company.

Lefebvre, H. (1968). El derecho a la ciudad. Península.

Lynch, G. (2017) Kyiv Maidan, Looking North II [Fotografía]. Kiev. https://flic.kr/p/2iVR9zc

Metzeltin, M. (2011). La construcción discursiva de la República de Chile. Boletín de Filología, 48(1), 239-253

Neira, H. (2004). La ciudad y las palabras. Universitaria.

Oliva, C. (2020). Monumentos en el estallido social como expresión material del derecho a la ciudad. Revista Planeo, 42. http://revistaplaneo.cl/2020/01/21/monumentosen-el-estallido-social-como-expresion-material-delderecho-a-la-ciudad/

Oliynyk, O. (2015). The Architectural Image of Kiev's Central Square as a Symbol of National Identity. De Urbanitate. Tales of Urban Lives and Space, (3), 81-92.
Orozco, K. (2018). El patrimonio cultural inmaterial de la Plaza Baquedano en Santiago de Chile. Territorios en Formación, (14), 74-94. http://polired.upm.es/index. php/territoriosenformacion/article/view/3893

Orozco, K. (2020). Patrimonio territorial: Una revisión teóricoconceptual. Aplicaciones y dificultades del caso español. Urbano, 23(41), 26-39. https://doi.org/10.22320/07183 $\underline{607.2020 .23 .41 .02}$

Ossa, C. y Richard, N. (2004). Santiago imaginado. Convenio Andrés Bello.

[Plaza Italia] (1938) [Fotografía]. Revista En Viaje. Empresa de los Ferrocarriles del Estado, año 5-6, № 51-62. Memoria Chilena. http://www.memoriachilena.gob.cl/602/ w3-article-72197.html

Rama, A. (1998). La Ciudad letrada. Arca.

Rodríguez, A. (1984). Por una ciudad democrática. Ediciones Sur.

Salazar, G. (2003). Ferias libres: espacio residual de soberanía ciudadana. Ediciones Sur.

Salcedo, R. (2002). El espacio público en el debate actual: Una reflexión crítica sobre el urbanismo post-moderno. EURE, 28(84), 5-19.https://dx.doi.org/10.4067/S025071612002008400001

Sandby, P. (1781). The Horse Race at Rome during the Carnival [Pintura]. British Museum. https://www.britishmuseum. org/collection/image/355644001

Segovia, O. y Neira, H. (2005). Espacios públicos urbanos: una contribución a la identidad y confianza social y privada. Revista INVI, 20(55), 166-182.

Segovia, O. y Oviedo, E. (2000). Espacios públicos en la ciudad y el barrio. En O. Segovia y G. Dascal (Eds.), Espacio público, participación y ciudadanía (pp. 51-69). Ediciones Sur. 
Senabre, D. (2008). La plaza mayor de Salamanca en el urbanismo del siglo XX. Ciudades: Revista del Instituto Universitario de Urbanística de la Universidad de Valladolid, (11), 191-209. https://doi.org/10.24197/ ciudades.11.2008.191-210

Sitte, C. (2013). The Art of Building Cities. City building according to its artistic fundamentals ( $1^{\text {a }}$ edición, 1889). Martino Publishing.
Topalov, C. (2010). L'Aventure des Mots de la Ville a travers le temps, les langues, les sociétés. Bouquins.

Varela, S. (1999). Espacio privado, espacio público: dialécticas urbanas y construcción de significados. Tres al Cuarto, 6, 22-24.

Vergara, F. (2011). El espacio cívico: el Paseo Bulnes como caso emblemático [Tesis de maestría no publicada, Facultad de Arquitectura, Diseño y Estudios Urbanos. Pontificia Universidad Católica de Chile].https://www.academia. edu/8713484/El_Espacio_Civico_El_Paseo_B 